\title{
Prevalence of Non-Albicans Candida in Samples Isolated From Human, Animals and Poultry and Methods of Identification With Special Reference to Antifungal Sensitivity Test.
}

Khafagy A.R. ${ }^{1}$, Ibrahim H.M. ${ }^{1}$, Taha M. ${ }^{2}$ and Eidaroos N.H. ${ }^{1}$ 1 Dept. of Microbiology, faculty of Veterinary Medecine, Suez Canal University, 2 Dept. of Microbiology, faculty of Veterinary Medecine, Zagazig University,

\begin{abstract}
During the last two decades, the frequency of fungal infections increased with serious infections. Among these fungi, Candida species was the predominant yeast infection of human and animals. The predominant Candida spp. isolated from human and animals were C.albicans but, the incidence of NAC Candida has been increased. In this study, a total of 205 samples were collected from different human and animal sources. The isolates were identified by phenotypic, commercial biochemical API $20 \mathrm{C}$ AUX kit and RFLP PCR and it was found that the RFLP PCR was the rapid, accurate and cost effective method of NAC identification. The most effective antifungal drug was amphotricin $\mathrm{B}$ and some isolates show resistance to common antifungal drugs as fluconazole.
\end{abstract}

Key words: NAC, RFLP PCR, antifungal sensitivity test.

\section{Introduction}

During the last 2 decades, the frequency of fungal infections increased that cause serious infections. Among the fungi, Candida species are opportunistic agent, which normally inhabitant in the intestinal tract, vaginal and oral cavity of human and animals (Pal et al., 2015).

Twenty years ago, the predominant Candida spp. that isolated from oral or systemic candidiasis was C.albicans with percentage of $80 \%$. Although $C$. albicans continues to be the most frequently isolated species, the number of infections caused by non-albicans species (NCAC) has increased significantly over the last 2 decades (Pincus et al., 2007) such as C.glabrata, C.tropicalis, C.parapsi llosis, C.krusei , C.guilliermondii , C.lusitaniae, C.kefyr, C.famata, and C.rugosa. NCAC species accounted for $10 \%-40 \%$ of all systemic candidiasis from 1970 to 1990 , and this proportion reached $35 \%-65 \%$ in the last 2 decades (Pal et al., 2015).

There are many factors that increase the frequency of NAC infections as sever illness and 
immunosuppression, young or old age, the increase using of broad spectrum antibiotics and empirical use of antimycotic drugs are reported to be associated with this change. The clinical signs of the infections caused by NAC species are indistinguishable, and several NAC spp. are inherently resistant or acquire resistance, or both, to commonly used antifungal drugs (Deorukhkar et al., 2014)

Allam and Salem (2012), studied the prevalence of Candida species isolated from sputum, urine and oral human candidiasis and found that C.albicans was the most frequently Candida spp. isolated from every specimen type with percentage of $44.2 \%$ and other Candida species isolated with lower percentage from each samples including C.glabrata, C.krusei, C.kefyr, C.tropicalis and C.stillatoidae with a percentage of $65.8 \%$ from total samples. $C$. albicans was the most common species associated with vulvovaginitis $(71.4 \%$ in pregnant women versus $64.7 \%$ in non pregnant women), followed by $C$. glabrata, C.tropicalis, , C.krusie and C.kefy (Emam et al., 2012), However Us and Cengiz, (Us and Cengiz, 2006) reported a lower percentage of $C$. albicans species $(53.2 \%)$ in pregnant patients.

Ghazaly (2001) studied the prevelance of yeast from mastitic milk and diarrheic calves where C.albicans isolated from milk with a percentage of $36 \%$ while NAC with percentage of $64 \%$. From diarrheic calves, C.albicans were isolated in low percentage $18.18 \%$ and NAC by $81.82 \%$.

Saleh et al. (2011) studied the prevalence of yeast spp. From different animals from different sources where the mycological examination revealed that the yeast isolates were representatives for only 3 species Candida albicans (110 isolates), Cryptococcous neoformans (20 isolates) and Rhodotorula rubra (66 isolates). The most frequently isolated yeast species were Candida species other than $C$. albicans from animal vaginal discharges [24.6\%], followed by $C$. albicans [15.6\%], R. rubra [7.5\%] and C. neoformans [2.24\%], while, the most frequently isolated yeast species from animal nasal discharges were $R$. rubra [17.8\%], $C$. albicans [16.2 \%], Candida spp. other than C. albicans [11.7 $\%$ ] and C. neoformans [1.67\%].

The present work was aimed to study the prevalence of NAC from human, animals and poultry samples and methods of identification and susceptibility of the isolated species to antifungal agents.

\section{Material and Methods}

A total of 205 samples were collected from human, animals and poultry. The numbers, types, condition of cases and sources are showen in table 1 .

All samples firstly isolated on SDA media then subcultured for 
morphological examination on RAT80 and CHROM Candida agar (Conda, France) for microscopic examination of fungal elements and macroscopic examinations of the color of the colony of different Candida species respectiveely. Twenty three samples that were identified by phenotypic methods were examined using API $20 \mathrm{C}$ AUX kit for biochemical identification (Biomerieux , France).

\section{Genotypic identification of}

Candida species (RFLP PCR).

Genomic DNA of 27 Candida isolates were extracted by BloodAnimal- Plant

DNA preparation kit (Jena Bioscience). Fungal specific universal primer pairs were used to amplify internal transcribed spacer 1(ITS1)-5.8S rDNA-ITS2 regions in all yeast isolates according to (Mohammadi et al., 2013), ITS-1(5-TCCGTAGGT GAACCTGCGG-3`) and ITS-4(5'TCCTCCGCTTATTCATATGC-

3 ). The amplification reaction was performed in a final volume of 25 $\mu 1$ containing $12.5 \mu \mathrm{l}$ master mix (Fermentase), $1 \mu \mathrm{l}$ of forward (ITS1) and reverse primer (ITS-4), $2 \mu 1$ of template DNA and the volume made up to $25 \mu \mathrm{l}$ with sterile nuclease-free water. The reaction mix was kept in the thermocycler (Eppendorf). The program was performed as follows: initial denaturation at $95^{\circ} \mathrm{C}$ for $5 \mathrm{~min}$, denaturation at $95^{\circ} \mathrm{C}$ for $30 \mathrm{sec}$, annealing at $56{ }^{\circ} \mathrm{C}$ for $30 \mathrm{sec}$, extension at $72{ }^{\circ} \mathrm{C}$ for $30 \mathrm{sec}$ and final extension at $72{ }^{\circ} \mathrm{C}$ for $5 \mathrm{~min}$ for 35 cycles.

RFLP was performed by using $M s p I$ enzyme according to company instructions ( Thermo Scientific) by $2 \mu 1$ of enzyme buffer, 1 Units of Msp I enzyme and $10 \mu \mathrm{l}$ of PCR product were added in a $200-\mu 1$ PCR tube and the volume was made up to $30 \mu \mathrm{l}$ with nuclease-free water. The reaction mix was incubated at $37^{\circ} \mathrm{C}$ for $5 \mathrm{~min}$. PCR products and RFLP products were electrophoresed in $1.5 \%$ and $2.0 \%$ agarose gel respectively, stained with Ethidium bromide $(0.5 \mu \mathrm{g} / \mathrm{ml})$ and visualized under UV light and photographed. Candida species that didn't identified by RFLP PCR were subjected for sequencing of the PCR products by 3500 genetic analyzer (applied biosystem, USA) Antifungal susceptibility testing by Disk diffusion (DD) technique by using fluconazole, ketoconazole, clotrimazole, amphotricine B, itraconazole and nystatin for Candida isolates. 
Table 1: The numbers, types, condition of cases and sources of samples.

\begin{tabular}{|c|c|c|c|c|c|}
\hline Type of samples & No. & $\begin{array}{c}\text { Condition of } \\
\text { cases }\end{array}$ & $\begin{array}{l}\text { Type of } \\
\text { samples }\end{array}$ & No. & Condition of cases \\
\hline $\begin{array}{l}\text { I Human } \\
\text { 1-Vaginal swabs } \\
\text { 2- Oral swabs } \\
\text { 3-Sputum samples } \\
\text { 4- Urine samples }\end{array}$ & $\begin{array}{l}68 \\
21 \\
12 \\
15 \\
20\end{array}$ & $\begin{array}{l}\text { VVC } \\
\text { Oral thrush } \\
\text { Respiratory } \\
\text { disorder } \\
\text { UTI }\end{array}$ & $\begin{array}{l}\text { II- Animals } \\
\text { A- Cows } \\
\text { 1- Milk samples } \\
\text { 2-Vaginal swabs } \\
\text { 3- Rectal swabs } \\
\text { B-Dogs } \\
\text { Ear swabs }\end{array}$ & $\begin{array}{l}90 \\
49 \\
24 \\
17 \\
\\
28 \\
\end{array}$ & $\begin{array}{l}\text { Mastitis } \\
\text { Reproductivedisorders } \\
\text { Diarrhea } \\
\text { Otitis externa }\end{array}$ \\
\hline & & & III- Poultry & 19 & Crop mycosis \\
\hline
\end{tabular}

UTI: Urinary tract infection, VVC: Vulvovaginal candidiasis.

\section{Results}

A total of 205 samples were collected from human, animals and poultry that give 143 positive culture (69.8\%). Numbers and percentage of positive yeast cultures from human, animals and poultry is showen in table 2 .

All yeast isolates were subcultured on RAT80 and CHROM Candida agar for morphological examination. Table (3) shows the numbers and percentage of Candida species that identified as Candida species by morphological methodswhich able to identify medically important species as C.albicans, C.tropicalis, C.krusei, C.glabrata and C.parapsilosis according to the color of the colonies on CHROM agar (fig.1) and fungal elements on RAT80 ( fig. $3,4,5$ )

With morphological examination, it was found that the predominant Candida species isolated from sputum, urine, VVC and oral candidiasis was C.albicans $(79.6 \%)$ while NAC represent $20.4 \%$. Morphological methods were able to identify all NAC from human isolates.

Concerning to cows samples, C.albicans was isolated with low percent $10.8 \%$ while NAC were isolated with high percentage 89.2\%. Morphological methods were able to identify C.albicans, C.tropicalis, C.krusei, C.glabrata and C.parapsilosis while 12 isolates couldn't be identified to the species level.

Swabs of dog's otitis externa revealed 12 Candida isolates where C.albicans was isolated with $16.7 \%$ while NAC isolated with percentage of $83.3 \%$.

Crop mycosis of poultry revealed 19 Candida isolates and C.albicans was isolated in high percentage $63.2 \%$ while NAC were $36.8 \%$.

\section{Biochemical identifications.}

Twenty two representative Candida species were further identified by API $20 \mathrm{C}$ AUX kit. The API $20 \mathrm{C}$ AUX kit was able to identify 13 examined NAC to the species level, 3 isolates that identified with morphological method as Candida spp. identified by API as 
Cryptococcus laurentii, 6 examined isolates gave unacceptable profile.

\section{Molecular methods}

Twenty four representative isolates that were identified by phenotypic methods and API $20 \mathrm{C}$ AUX were subjected for further identification by RFLP PCR (fig, 6 to 13)

Table 4, shows isolates that identified with phenotypic methods, API $20 \mathrm{C}$ AUX and RFLP PCR.

RFLP PCR proved to be the accurate, rapid and simple method of NAC where, the 3 NAC that identified by API as Cryptococcus laurentii were identified as C.kefyr by RFLP PCR, one Candida spp. was identified by API as C.rugosa and identified as C.krusei with RFLP PCR, 4 isolates that gave unacceptable profile with API kit were found to be mixed isolates that clearly identified by RFLP PCR (fig. 12,13 ). Two isolates didn't identified by both API and RFLP PCR.

Six isolates that had different results with API and RFLP PCR were subjected for sequencing for confirmation of the results (table 5) The sequencing proved that the results of RFLP PCR were accurate as the 3 isolates that identified with morphological method as Candida spp. identified by API as Cryptococcus laurentii were proved to be C.kefyr, the other isolate that identified as C.rugosa by API was proved to be C.krusei which was the same result of RFLP PCR. C.pelliculosa was truly identified by API in comparing with sequencing and RFLP PCR couldn't identify it.

\section{Antifungal sensitivity test.}

Concerning to antifungal sensitivity test, all isolates showed sensitivity to amphotricin B and clotrimazole except C.pelliculosa that showed resistance against clotrimazole. C.parapsillosis and C.glabrata were sensitive to all tested antifungal discs. C.albicans showed resistance to fluconazole and ketoconazole, C.kefyr were resistant to itraconazole and ketoconazole and C.inconspicua showed resistance against fluconazole.

Table (2): Numbers and percentage of positive yeast cultures from human, animals and poultry.

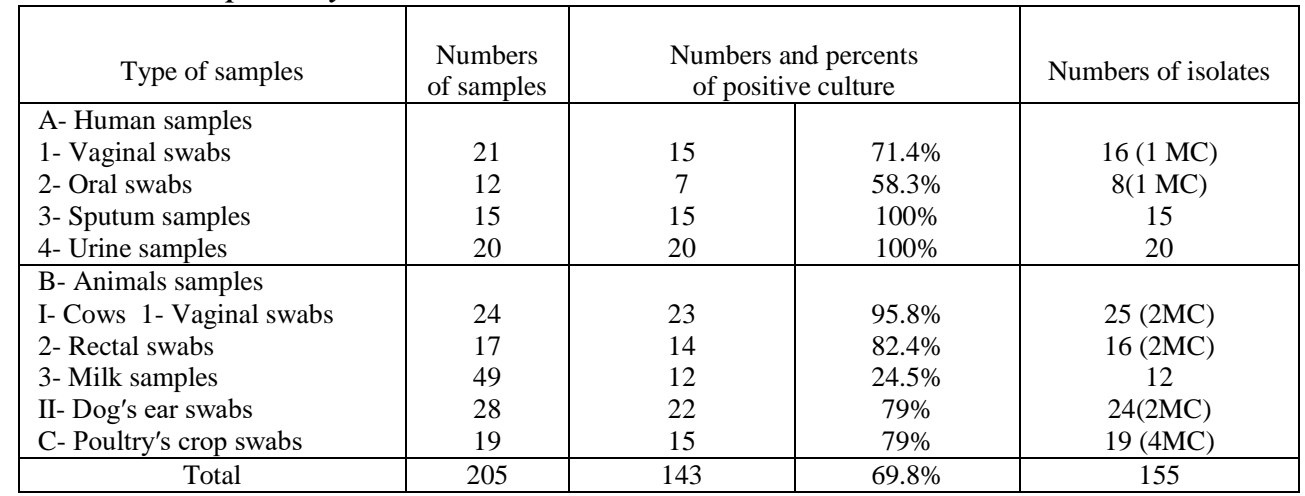


MC: Mixed culture
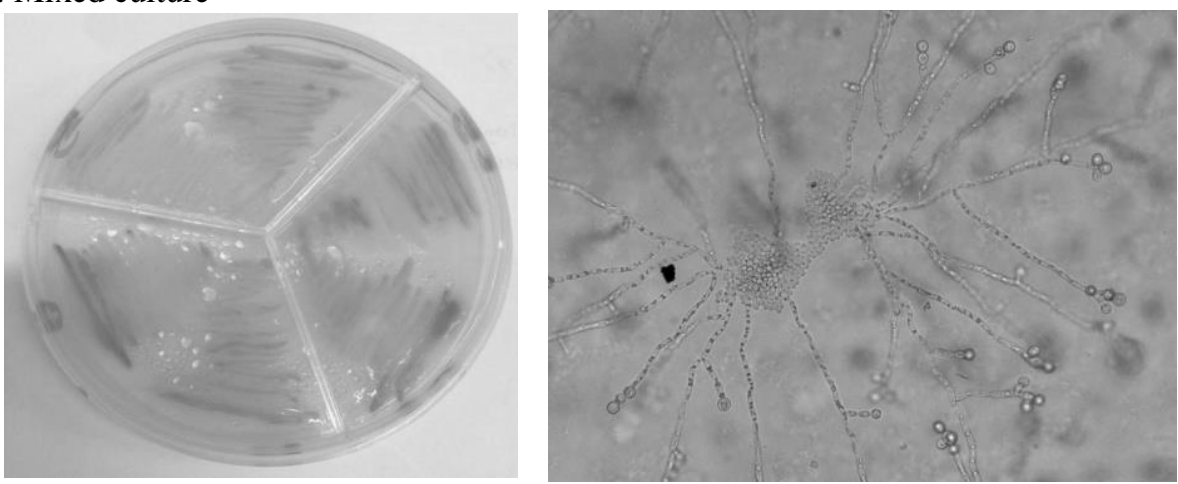

Fig.(1): CHROM Candida agar: C.albicans (green), C.krusei (purple), C.glabrata and C.parapsillosis (pink

Fig.2: C.albicans on RAT shows blastospores, pseudohyphae \& chlamydoconidia
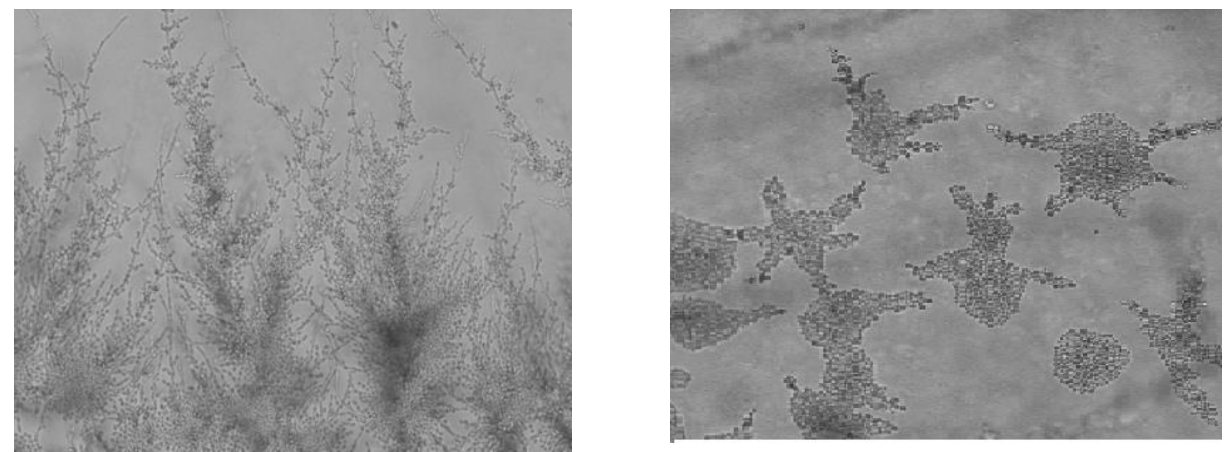

Fig.3: C.parapsillosis on RAT show branched pseudohyphae that carry abundant of blastospores.

Fig.4: Candida species on RAT show primitive pseudohyphae and blastospores.

Table (3): Numbers \& percentage of Candida spp. identified by phenotypic methods.

\begin{tabular}{|c|c|c|c|c|c|c|c|}
\hline & Identification & No. & $\%$ & & Identification & No. & $\%$ \\
\hline \multirow[t]{2}{*}{$\begin{array}{c}\text { I- } \\
\text { Human }\end{array}$} & \multirow[t]{2}{*}{$\begin{array}{c}\text { C.albicans } \\
\text { C.parapsilosis } \\
\text { C.glabrata } \\
\text { C.krusei } \\
\text { C.tropicalis }\end{array}$} & $\begin{array}{c}47 \\
5 \\
5 \\
1 \\
1\end{array}$ & \multirow[t]{2}{*}{$\begin{array}{l}79.6 \\
8.5 \\
8.5 \\
1.7 \\
1.7\end{array}$} & \multirow[t]{2}{*}{$\begin{array}{c}\text { II- } \\
\text { A-Cows }\end{array}$} & \multirow[t]{2}{*}{$\begin{array}{c}\text { C.albicans } \\
\text { C.parapsilosis } \\
\text { C.glabrata } \\
\text { C.krusei } \\
\text { C.tropicalis } \\
\text { Candida spp. }\end{array}$} & $\begin{array}{c}4 \\
3 \\
5 \\
11 \\
1 \\
12 \\
\end{array}$ & \multirow[t]{2}{*}{$\begin{array}{c}10.8 \\
8.1 \\
13.5 \\
29.7 \\
2.7 \\
32.4\end{array}$} \\
\hline & & 59 & & & & 37 & \\
\hline \multirow[t]{2}{*}{$\begin{array}{c}\text { III- } \\
\text { Poultry }\end{array}$} & \multirow[t]{2}{*}{$\begin{array}{c}\text { C.albicans } \\
\text { C.glabrata } \\
\text { C.parapsilosis } \\
\text { C.krusei }\end{array}$} & $\begin{array}{l}12 \\
2 \\
3 \\
2\end{array}$ & \multirow[t]{2}{*}{$\begin{array}{l}63.2 \\
10.5 \\
15.8 \\
10.5\end{array}$} & \multirow[t]{2}{*}{ B-Dogs } & \multirow[t]{2}{*}{$\begin{array}{c}\text { C.albicans } \\
\text { C.parapsilosis } \\
\text { Candida spp. }\end{array}$} & $\begin{array}{l}2 \\
3 \\
7\end{array}$ & \multirow[t]{2}{*}{$\begin{array}{c}16.7 \\
25 \\
58.3\end{array}$} \\
\hline & & 19 & & & & 12 & \\
\hline
\end{tabular}


Table (3): Identification of yeast isolates by phenotypic, biochemical \& molecular methods

\begin{tabular}{|c|c|c|c|}
\hline No. & $\begin{array}{c}\text { Phenotypic } \\
\text { identification }\end{array}$ & Api 20 C AUX & RFLP PCR \\
\hline 1 & C.albicans & C.albicans & C.albicans \\
\hline 2 & C.glabrata & C.glabrata & C.glabrata \\
\hline 3 & Candida spp. & C.laurentii & C.kefyr \\
\hline 4 & Candida spp. & C.krusei & C.krusei \\
\hline 5 & Candida spp. & C.laurentii & C.kefyr \\
\hline 6 & Candida spp. & C.norvegenesis & C.norvegenesis \\
\hline 7 & Candida spp. & C.rugosa & C.rugosa \\
\hline 8 & Candida spp. & C.krusei & C.krusei \\
\hline 9 & Candida spp. & C.pelliculosa & Not identified \\
\hline 10 & Candida spp. & C.rugosa & c.krusei \\
\hline 11 & Candida spp. & C.krusei & C.krusei \\
\hline 12 & Candida spp. & C.krusei & C.krusei \\
\hline 13 & Candida spp. & C.krusei & C.krusei \\
\hline 14 & Candida spp. & Not identified & Not identified \\
\hline 15 & Candida spp. & Cryp.laurentii & C.kefyr \\
\hline 16 & Candida spp. & C.inconspicua & C.inconspicua \\
\hline 17 & C.parapsillosis & C.parapsillosis & C.parapsillosis \\
\hline 18 & Candida spp. & Not identified & Not identified \\
\hline 19 & Candida spp. & Not identified & Mixed (C.glabrata \& C.kefyr) \\
\hline 20 & Candida spp. & Not identified & Mixed (C.glabrata \& C.kefyr) \\
\hline 21 & Candida spp. & Not identified & Mixed (C.glabrata \& C.albicans) \\
\hline 22 & Candida spp. & Not identified & Mixed (C.albicans \& unidentified yeast) \\
\hline
\end{tabular}
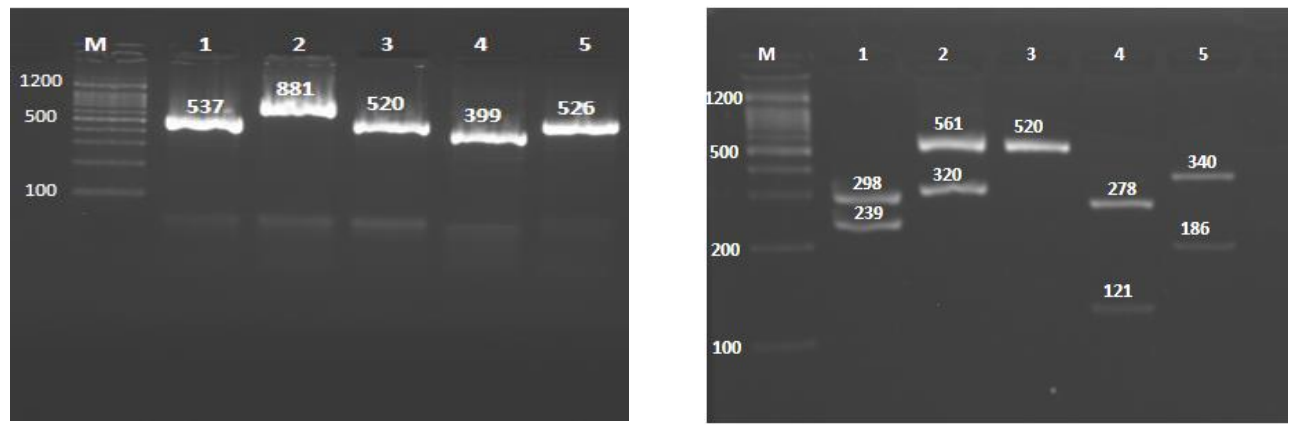

Fig. (6): PCR product of Candida spp. lane M, $100 \mathrm{pb}$ ladder, lane 1, C.albicans, lane 2, C.glabrata, lane 3, C.parapsillosis, lane 4,C.rugosa, lane 5, C.tropicalis.

Fig. (7): RFLP-PCR product of Candida spp. lane M, 100 pb ladder, lane 1, C.albicans, lane 2, C.glabrata, lane 3, C.parapsillosis, lane 4,C.rugsa, lane 5, C.tropicalis. 

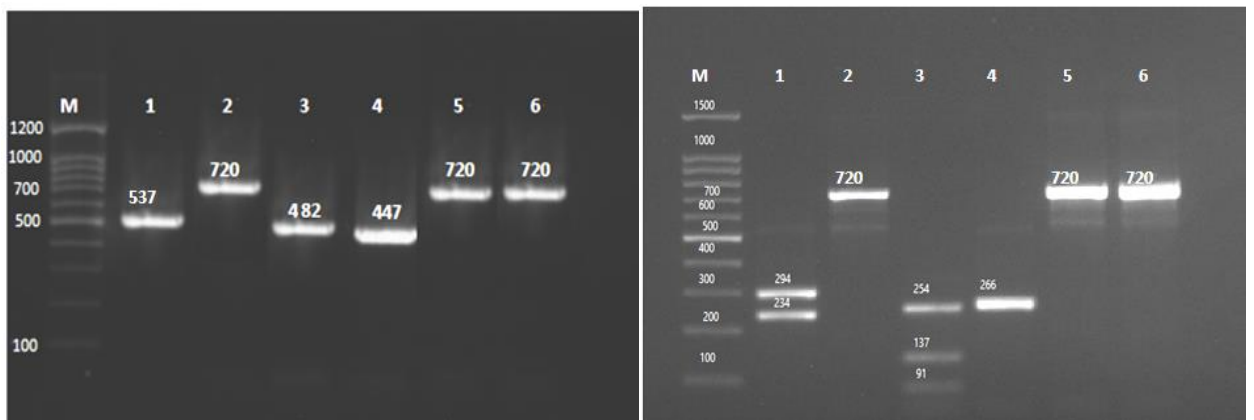

Fig (8): PCR product of Candida spp. lane M, 100 pb ladder, lane 1, C.albicans, lane 2,5,6 C. kefyr, lane 3, P.manchurica, lane 4, C.inconspicua.

Fig (9): RFLP-PCR product of Candida spp. lane M, $100 \mathrm{pb}$ ladder, lane 1, C.albicans, lane 2,5,6 C. kefyr, lane 3, P.manchurica, lane 4, C.inconspicua.

Fig. (10): PCR product of Candida spp. lane M, $100 \mathrm{pb}$ ladder, lane 1, C.rugosa, lane 2, C.norvogenesis, lane 3,4,5,8,9 C.krusei, lane 6, C.ethanolica lane 7, C.pelliculosa
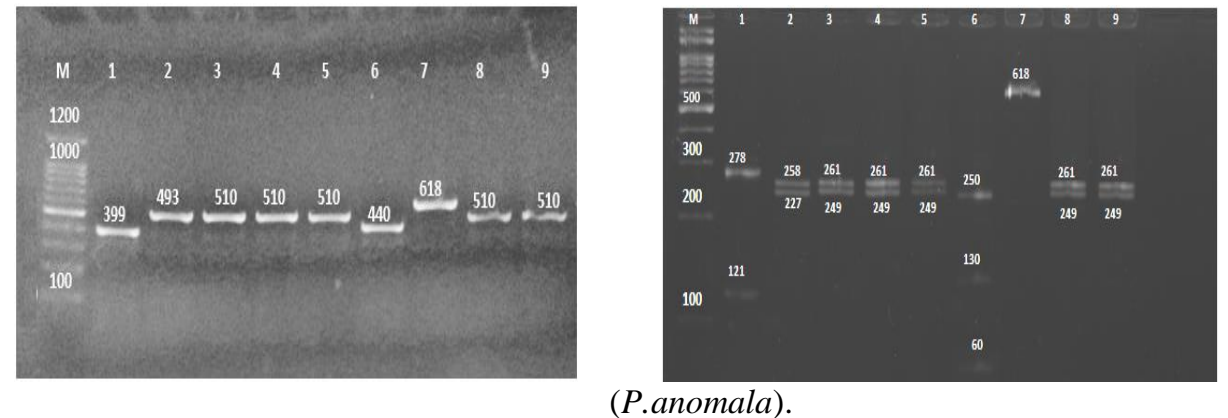

Fig.(11): RFLP-PCR product of Candida spp. lane M, $100 \mathrm{pb}$ ladder, lane 1, C.rugosa, lane 2, C.norvogenesis, lane 3,4,5,8,9 C.inconspicua, lane 6, C.ethanolica, lane 8, C.pelliculosa.
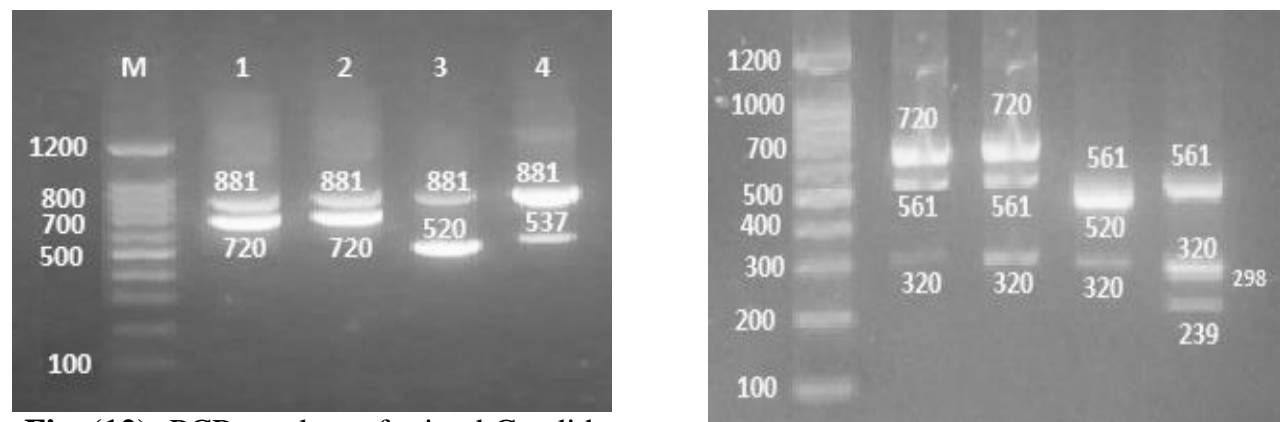

Fig. (12): PCR product of mixed Candida spp.

lane M, $100 \mathrm{pb}$ ladder, lane 1,2, C.glabrata and C.kefyr, lane 3, C.glabrata and C.parapsillosis, lane 4, C.albicans and C.glabrata.

Fig. (13): RFLP-PCR product of mixed Candida spp. lane M, $100 \mathrm{pb}$ ladder, lane 1,2, C.glabrata and C.kefyr, lane 3, C.glabrata and C.parapsillosis, lane 4, C.albicans and C.glabrata. 
Table (4): Correlation between identification by API kits, RFLP-PCR and sequencing for 6 isolates.

\begin{tabular}{|c|c|c|c|}
\hline $\begin{array}{l}\text { No. of } \\
\text { isolates }\end{array}$ & API identification & $\begin{array}{c}\text { RFLP-PCR } \\
\text { identification }\end{array}$ & Sequencing of DNA \\
\hline 3 & $\begin{array}{l}\text { Cryptococcus } \\
\text { laurentii }\end{array}$ & C.kefyr & $\begin{array}{l}\text { Kluyveromyces marxianus } \\
\text { (the perfect state of C.kefyr) }\end{array}$ \\
\hline 1 & C.pelliculosa & Not identified & $\begin{array}{c}\text { Pichia anomala } \\
\text { (the perfect state of C.pelliculosa) }\end{array}$ \\
\hline 1 & Not identified & Not identified & C.ethanolica \\
\hline 1 & C.rugosa & C.krusei & $\begin{array}{c}\text { Pichia kudriavzevii } \\
\text { (the perfect state of } \text { C.krusei) }\end{array}$ \\
\hline
\end{tabular}

\section{Discussion:}

The number of infections caused by non-albicans Candida species (NAC) has increased significantly over the last 2 decades such as C.glabrata, C.tropicalis, C. .krusei, C.parapsillosis , C.guilliermondii , C.lusitaniae, C.kefyr, C.famata, and C.rugosa. The clinical manifestations of infections caused by diferent member of NAC spp. are usually indistinguishable, but several NAC spp. are inherently resistant or acquire resistance, or both, to commonly used antifungal drugs So, rapid and accurate identification is important for detection of susceptible antifungal drugs.

The present work aimed to study the prevalence of NAC from candidiasis or Caandida infections from human, animals and poultry and study the different

The predominant Candida species that isolated from human was C.albicans $(79.6 \%)$ while NAC were $20.4 \%$, these results are in line with (Allam and Salem, 2012) who isolated C.albicans as the predominant Candida spp. from sputum, urine and oral candidiasis as C.albicans has virulence factors more than NAC that aid in establishment of the infection as such as germ tube formation, adherence (biofilm formation), dimorphism, phenotypic switching, toxins and hydrolytic enzymes (Calderone and Fonzi, 2001). The widespread abuse of antifungal drugs, use of topical dose or single oral and long term of oral azole lead to increase in the incidence of NAC yeast infection that are relatively non pathogenic (Neerja et al., 2006).

Concerning to cow samples, C.krusei was the predominant isolate $(29.7 \%)$, C.albicans isolated with low perecentage (10.8\%), these results are in agreement with (Tartor, 2013) who isolated C.krusei as the predominant isolate. Some yeast species considered with other potentially pathogenic microorganisms which may cause diarrhea under certain conditions but are not considered primary enteric pathogens. Conditions 
produced in the digestive tract by the diarrhea favor the proliferation of the yeast. Antibacterial treatment of such cases, might be not only unnecessary but counterproductive, resulting in the intensification of the microbial imbalance in favor of the mycotic flora in the GIT. In this study, yeasts isolated from diarrheic calves that not respond to antibiotic treatment with a percentage of $82.35 \%$ where C.albicans $(12.5 \%)$, C.glabrata (31.25\%), C.krusei $(18.75 \%)$ and Candida spp. (31.25\%) that involve 3 C.kefyr, 1 C.pelliculosa and 1 C.ethanolica. These results is in line with (Elad et al., 1998) who isolated C.glabrata as the predominant cause of calves diarrhea and also isolated C.kefyr, C.krusei, C.rugosa and another NAC species from diarrheic calves.

The reproductive tracts of different animals are the major reservoir of yeasts such as $C$. albicans and $C$. neoformans. In this study, 15 Candida species were revealed from vaginal swabs where, C.krusei (5) was the predominant isolate $(35.7 \%)$ while C.albicans (2) $(14.3 \%)$, and totally NAC were $(85.7 \%)$ from the vagina of cows with vaginitis and reproductive disorders which were C.parapsillosis, C.tropicalis, C.glabrata, C.kefyr and C.inconspicua . These results sre in agreement with Saleh et al. (2011) who found that the most frequently isolated yeast species were Candida species other than $C$. albicans (NAC) from animal vaginal discharges [24.6\%], followed by C. albicans $[15.6 \%]$.

Candida species are often responsible for mastitis. This phenomena is due to frequent use of antibiotics in the treatment and in the dry period. Antibiotic therapy lead to perturbation in udder homeostasis, inhibition of $\mathrm{T}$ cells and neutrophil activity and inconsequence to stimulation of yeast growth (Kano et al., 2001). It is well established that the yeasts of the genus Candida, for example, are capable of utilizing antibiotics as source of nitrogen like penicillin and ampicillin . The fungal invasion may be facilitated by injury to the udder's epithelium due to uptake of large doses of antibiotics that cause reduction in the vitamin $\mathrm{A}$ which are responsible for the health of epithelium (Noris et al., 2007). In this study, C.albicans didn't isolated from mastitic milk and C.krusei was the predominant. C.parapsillosis, C.rugosa, C.glabrata, C.inconspicua and C.norvogenesis also isolated. This result is in agreement with (Czernomysy-Furowicz et al., 2008).

As regard to crop mycosis, C.albicans $(63.15 \%)$ was the most Candida species isolated followed by C.parapsillosis, C.glabrata and C.krusei isolated from crop thrush. This results are in line with (Tartor, 2013) and (Keymer 1982) who concluded that the specific instance of avian crop candidiasis is either primary or secondary mostly due to 
C.albicans, C.krusei and C.tropicalis . (Kano et al., 2001) also isolated C.parapsillosis from crop mucosa in cockatiel.

In this study, Candida species were identified by phenotypic methods, API $20 \mathrm{C}$ AUX biochemical kit and molecular methods.

Phenotypic methods include subculture of isolates on RAT80 and CHROM agar. This method was able to identify C.albicans from all samples from human, animals and poultry and other medically important Candida species including C.tropicalis, C.parapsillosis, C.glabrata and C.krusei.

Concerning to RAT 80, more than one species have the same elements as C.krusei and C,rugosa show primitive hyphae while C.glabrata and C.inconspicua characterized by blastospores only. By CHROM agar, some Candida spp. that have the same micromorpholgy on RAT 80 can be identified as $C$.krusei give purple color while C.rugosa had pink color, C.glabrata gave pink colonies with white borders while C.inconspicua had pink colored colonies. So, identification by morphological methods should be dependent on the 2 media and this time consuming and in the same time, this method couldn't identify all NAC to the species level accurately. So, accurate identification of all NAC couldn't be performed by morphological methods.
Comparing between API 20 C AUX kit and RFLP PCR, API can identify $56.5 \%$ of examined isolates that confirmed with PCR, 3 Candida spp. were identified by API as Cryptococcus laurentii were identified by PCR as C.kefyr, 4 tested isolates couldn't be identified by API and it found to be mixed isolates with PCR. There were 2 species that couldn't identify by API and RFLP PCR and 1 C.krusei identified as C.rugosa by API and identified by PCR as C.krusei.

Isolates that didn't identified and samples that had different results with API and RFLP PCR were sequenced and it was found that the 3 isolates that identified by API as Cryptococcus laurentii, identified by sequencing as Kluyveromyces marxianus (the perfect state of C.kefyr), one isolate identified as C.rugosa by API and identified by PCR as C.krusei was identified by sequencing as Pichia kudriavzevii (the perfect state of C.krusei), one isolate identified as C.pelliculosa by API and identified by sequencing as P.anomala (the perfect state of C.pelliculosa), 2 species couldn't identified by both API and RFLP PCR that identified by sequencing as C.ethanolica and P.mandchurica. Kluyveromyces marxianus, Pichia kudriavzevii and C.ethanolica not present in API database and mixed cultures didn't involved in the API database, so, with reference to the database, API $20 \mathrm{C}$ AUX was able to identify $100 \%$ of examined 
Candida species. This in agreement with (Gündes et al., 2001).

RFLP PCR could identify all Candida species accurately to the species level except 2 species that couldn't be identified because of no previous work (to my knowledge ) used ITS1 and ITS4 for amplification of these species.

RFLP-PCR method proved to be simple, cost-effective and rapid method for differentiation between all Candida species that is applicable in clinical laboratories. In this study, all examined isolates were sensitive to amphotricin B as amphotricin B has fungicidal effect against all Candida spp. Amphotricin B interact with fungi membrane ergosterols to produce an aggregate that forms a transmembrane channel, allowing the cytoplasmic contents to leak out and subsequent fungal cell death but amphotricin B has nephrotoxic effect so, it is not used as first choice or first line of treatment. (Hung, 2008)

\section{References}

Allam A.A. and Salem I.M. (2012): Evaluation of rapid molecular identification of clinically important Candida species isolated from immunocompromised patients using RF-PCR. Journal of American Science, 8:463-468.

Calderone RA \& Fonzi WA. (2001): Virulance factors of Candida albicans. Trends Microbiol 9:327-335.
Czernomysy-Furowicz, Karakulska J. and Silecka A(2008): Etiological agents of mastitis in dairy cows on a farm in the West Pomeranian region. Acta Sci. Pol., Zootechnica 7 (1) : 3-10.

Deorukhkar S.C., Saini S. and Mathew S. (2014): Non-albicans Candida Infection: An Emerging Threat. Interdisciplinary Perspectives on Infectious Diseases. Volume 2014, Article ID 615958, 7 pages.

Elad D., Brenner J., Markovics A., Yakobson B., Shlomovitz S. \& Basan J. (1998): Yeasts in the gastrointestinal tract of preweaned calves and possible involvement of Candida glabrata in neonatal calf diarrhea. Mycopathologia 141: 7.

Emam S.M., Abo Elazm A.A and Morad W.A. (2012): Exoenzymes Production and Antifungal Susceptibility of Candida Species Isolated from Pregnant Women with Vulvovaginitis. J Am Sci ;8(12):1392-1399.

Ghazaly. N.H. (2001): studies on the methods of the identification of veterinary medical important yeasts. M.V.Sc. Thesis (Microbiology faculty of Veterinary Medicine, Zagazig University.

Gündes SG, Gulenc S, Bingol R. (2001): Comparative performance of Fungichrom I, Candifast and API 20C Aux systems in the identification of clinically significant yeasts. J Med Microbiol ; 50: 1105_1110.

Hung I.F. (2008): Update on Antifungal Treatment in 
Neutropenic Patients. Medical Bulletin, VOL.13 NO.8.

Kano R, Sukamoto Y, Hanahachi A, Kamata H, Fukuda Y, Fujiwara $K$ and Hasegawa $A$ (2001): Molecular identification of Candida parapsillosis from crop mucosa in a cockatiel. Diagn. Invest., 13:437-439.

Keymer I.F. (1982): Mycoses. In: Diseases of the cage and aviary, ed2. Petrak LM, pp. 601-602. Lea $\&$ Febiger, Philadelphia, PA.

Mohammadi R., Mirhendi H., Matehkolaei A.R., Ghahr M., Shidfar M.R., Jalalizand N. and Makimura K. (2013): Molecular identification and distribution profile of Candida species isolated from Iranian patients. Medical Mycology. 51:657-663.

Neerja J, Aruna A. and Paramjeet G. (2006): Significance of Candida culture in women with vulvo-vaginal symptoms. J Obstet Gynecol India. 56(2): 139-141.

Noris M, Casiraghi F, Todeschini M, Cravedi P, Cugini D, Monteferrante G, Aiello S, Cassis L, Gotti E, Gaspari F, Cattaneo $D$, Perico $N$ and Remuzzi $G$ (2007): Regulatory $T$ cells and $T$ cell depletion: role of immunosuppressive drugs. J. Am. Soc. Nephrol. 18, 1007-1018.
Pal M., Gebrezgabher W., Samajpati N, and Manna A.K. (2015): Growing role of nonCandida albicans Candida species in clinical disorders of humans and animals. J. Mycopathol. Res. 53(1) : 41-48.

Pincus D. H., Oregana S. \& Chatellier S. (2007): Yeast identification: past, present, and future methods. Medical Mycology March, 45: 97-121.

Saleh H.A. , Moawad A.A, ElHariri M. and Refai M.K. (2011): Prevalence of Yeasts in Human, Animals and Soil Sample at ElFayoum Governorate in Egypt. Intl. J. Microbiol. Res., 2 (3): 233-239

Tartor Y.I (2013): Studies on spectroscopy as a method for identification of yeasts and dermatophytes isolated from human and animals with special reference to antifungal sensitivity test for identified isolates. $\mathrm{PhD}$ thesis of Vet. Med. Science, Mycology Zagazig University.

Us E.and Cengiz A.S. (2006): Prevalence and phenotypic evaluation of Candida dubliniensis in pregnant women with vulvovaginal candidiasis in a university hospital in Ankara. Mycoses. 50: 13-20. 


\section{الملخص العربي}

خلال العقدين الماضيين، ارتفعت وتيرة الالتهابات الفطرية مع الإصابات الخطيرة. ومن بين هذه الإنه

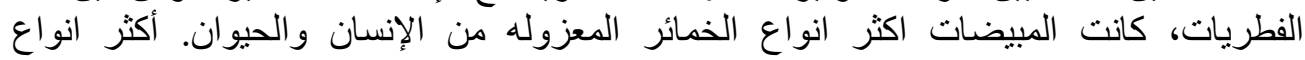

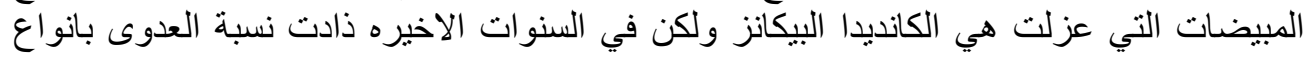

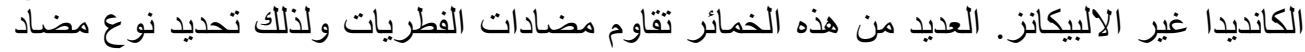

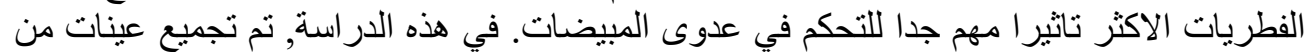

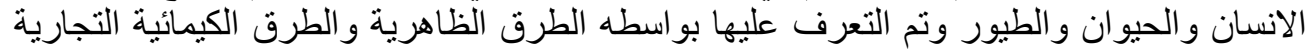

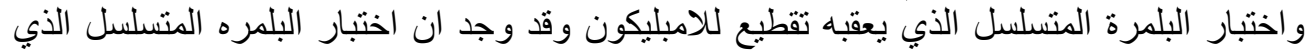

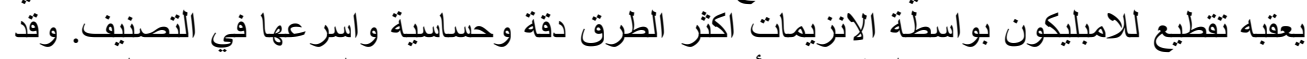

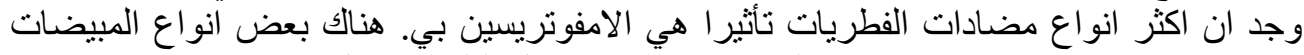

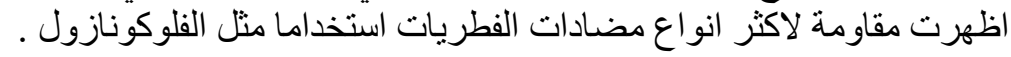

